\title{
Social networks: the future of marketing for small business
}

Lisa Harris and Alan Rae

Lisa Harris is Senior

Lecturer in Marketing at the University of Southampton School of Management, Southhampton, UK. Alan Rae is Managing Partner of $\mathrm{Al}$ Consultants, Sussex, UK.

\begin{abstract}
Introduction
This paper reviews recent developments in online marketing strategy which demonstrate the growing power of online communities in building brand reputations and customer relationships. Our work draws upon the results of an ongoing research project which is investigating the use of new technologies by entrepreneurial businesses in West London. We review recent trends and examine the emerging role of social networking within an integrated marketing strategy that combines online and offline elements in a "package" best suited to meeting identified customer needs. A range of examples from our 30 case study businesses are drawn upon to illustrate some of the opportunities and threats associated with these new marketing priorities. We conclude that social networks will play a key role in the future of marketing; externally they can replace customer annoyance with engagement, and internally they help to transform the traditional focus on control with an open and collaborative approach that is more conducive to success in the modern business environment.
\end{abstract}

\section{Brief overview of trends}

The internet impacts business innovation by expanding reach and minimizing the time-lag to market. Not so long ago the goal of an online marketing campaign might only have been to entice the consumer to click through to a company's website, but now the objective is to create "sustained engagement" with the consumer. The growing popularity of websites such as YouTube and Facebook demonstrates how the internet is changing; users are no longer simply downloading static data, but are increasingly uploading and sharing content among themselves, leading to a proliferation of social networks and other user-generated content sites. $\mathrm{Li}$ and Bernoff (2008) refer to this fundamental transfer of power from institutions to individuals and communities as "the groundswell" and it forms the title of their thoughtful and thoroughly researched book on the topic. The authors' predictions of significant change in marketing practice are supported by a number of respected authors such as Weber (2008) and Godin (2008).

\section{Web 2.0}

This latest iteration of the internet has become known as "Web 2.0". In many ways it represents a return to its roots. The internet started life as a peer-to-peer communication tool to exchange data among a number of users, allowing members of the scientific community to collaborate and share information easily. Today community sites such as TripAdvisor encourage users to review services that they have experienced for the benefit of other users who are considering their own possible purchases. These peer reviews are regarded as far more trustworthy than traditional promotional materials that have been produced by the company itself. Many people in the UK now buy a product or service directly because of comments posted on a community by other consumers. This trend is fundamentally 
changing the relationship between businesses and their customers, particularly as the information (which may of course be positive or negative) is displayed in a very public indeed global - forum.

\section{Global brands try blogging ...}

Businesses cannot expect to keep control of their marketing message while at the same time allowing a transparent voice to their staff and customers through a blog or other online forum. Negative feedback cannot be hidden without exposing the business to charges of censorship that can destroy its credibility. The New York Times (2008) reports on the case of Walmart, which had to shut down its early blogging efforts as customers felt they lacked authenticity, regarding them as thinly-veiled PR exercises. The company has recently "bitten the bullet" again with a new blog called Check Out (http://checkoutblog.com) after lengthy consultation with the authors of successful blogs about how to develop an appropriate blogging policy. The blog is written by ordinary employees who are encouraged to speak freely (and often critically) about Walmart and its suppliers without corporate editing. It remains to be seen how successful this initiative will be, but the company has clearly learned from past mistakes and is prepared to try again with an approach that challenges its traditional organizational culture. In a similar vein, Li (2007) notes how General Motors was able to identify vocal critics from postings on the company blog, and in response invited these people to visit the factory where the company demonstrated how the problems they raised had been addressed. As a consequence, many of the critics were converted into active and enthusiastic supporters of the brand.

\section{Online communities}

\section{Good and bad examples}

Online communities have evolved considerably since the early days of news groups and chat rooms. They offer a simple means of overcoming the lack of human contact online and hence can meet consumers' social activity needs. Cisco (www.cisco.com) is a successful example of a company that has fostered customer communities and saved significant customer support costs by letting customers help themselves to technical support information via web communities. After Cisco put the technical support function online, customers began to compete with each other to answer queries that had been posted by other customers. Amazon has pioneered the process of "collaborative filtering" whereby recommendations are made to customers on the basis of what other customers buying the same book also bought. Together with displays of unedited customer reviews, this strategy contributes towards the creation of a community of people with similar interests who will trust and act upon the recommendations of others in the group. By encouraging customers to try out other items in this way, not only are total sales increased but also their scope - customers may not otherwise have ventured outside the Top 100 books without a specific recommendation that was probably unknown to them beforehand. Amazon now makes one third of its sales from outside the top 130,000 titles, and these books are unlikely to be offered at a discounted price.

On the negative side, the vigilante site www.untied.com is devoted to criticism of the customer service provided by United Airlines. Originally established by one disgruntled passenger, the site developed momentum as others contributed their own horror stories about the service quality and the company presented a series of textbook examples of how not to handle complaints. A recent example of a successful online community is www. getsatisfaction.com which provides a forum for customers to raise questions or complain about a wide range of companies, and for the resulting discussions to be displayed for other enquirers to search and view. Companies can elect to participate in the discussions in order to address issues raised by customers, in which case the active involvement of their employees is clearly flagged up. The flip side is that companies electing not to participate in the community discussions about their products and services can come across as secretive and unhelpful, and their brand image can be damaged as a result. 
Most online communities are currently at a relatively early evolutionary stage and have yet to be subjected to serious study, but from the company perspective the information posted on relevant community sites can provide valuable research data about such issues as product quality, how useful the website content is and how easy it is for customers to navigate and find what they are looking for. Conversations within online communities can encourage customers to co-create brand values and spread a message virally, rather than just passively consume brands as per the traditional marketing model. Think for example of how customer-to-customer interaction has contributed to the growth of the eBay brand. eBay's transparent service quality rating system allows prospective customers to evaluate potential suppliers in terms of their trustworthiness and reliability based on the experiences of other customers' transactions with that supplier.

Alongside the growth in company or industry-specific communities, more generic online social networking has become hugely popular in recent months. According to Goad and Mooney (2008) the most popular social networks in the UK are currently Facebook, Bebo and My Space, with market shares of 38, 28, and 19 percent, respectively. The authors cite figures showing that a larger proportion of the UK population have chosen to communicate with friends through social networks than by e-mail services such as Hotmail since October 2007 , and that the age profile of users is rising rapidly with strongest growth amongst the over 55s. Businesses are now recognizing the potential of these communities for the development of their brands and to build relationships with key customers. For example, the retailer Primark is surfing the wave with its Primark Appreciation Society Facebook Group which has over 100,000 members who are signed up "fans" of the Primark brand. Satisfied customers brag about the bargains they have found in the stores or campaign for the opening of new Primark outlets in their locality. On the same discussion boards, however, disgruntled customers also complain about the poor quality of goods they have purchased from the company.

The Royal British Legion ran a successful campaign in November 2007 whereby people could download an application to display a poppy on their Facebook profile. This promoted both an increase in the total number of visitors to the British Legion website, and also attracted a younger demographic profile than the Legion does through its traditional communication channels since 31 percent of the site visitors were aged 18-34 (Goad and Mooney, 2008). Facebook needs to operate as a profitable business of course, but the danger is that over-commercialization of a social network through advertising may prompt an exodus of users towards the "next big thing", as well as damage relationships between consumers and participating brands if interactions within the network are not managed carefully. At present, Facebook's policy is for users to receive a maximum of two sponsored messages per day.

\section{Microblogging - the next big thing?}

Another form of social networking activity to emerge recently is "microblogging" through sites such as Twitter, Pownce and Jaiku. Using these sites, people can communicate with their chosen network in a real time, heavily abbreviated content format (maximum 140 characters) that may include a url. For example, a typical message may read "click here for a discount on my latest book published on Amazon today". These messages can reach a wider audience when they are fed through to display in the author's blog or Facebook profile. Dell Computers is using Twitter to sell off clearance items to its brand champions who are following Dell at: http://twitter.com/delloutlet. A business seeking to raise awareness of a new electronic product, for example, would be keen to recruit Twitter users to its cause because they are: 
- early adopters of new technologies;

- well-educated, with high profile careers and large salaries;

- receptive to relevant advertising and are likely to talk about products within the Twitter community to "spread the word"; and

- very influential within their own community and potentially able to develop the profile of the brand through its endorsement when interacting with their followers.

By actively courting both key players within these niche social networks and the identified vocal "fans" from Facebook groups, businesses may find that they can raise brand awareness and build customer relationships at a very low cost to themselves. What prevents many from doing so is the fear that an influential brand advocate who has a bad experience may start spreading negative messages about the company. In the next section we will discuss the experiences of our case study businesses and attempt to draw out some "best practice" guidelines from these early adopters for the benefit of others who may be considering whether to integrate social networking into their marketing operations.

\section{Social networking by our case study businesses}

Some of the businesses we studied have become quite sophisticated at using the collaboration and advocacy intrinsic to social networking to promote and grow their businesses. It requires a certain robustness of spirit to be prepared to take criticism along with the praise, but for those prepared to operate transparently the benefits are there to be taken. Table I summarizes the specific activities undertaken by the main players and the nature of their business.

\section{Effective collaboration using Ecademy}

Many of our interviewees were active on Ecademy, a business networking platform which uniquely combines a substantial face-to-face networking component with blogs, special interest online discussion groups and meetings, allowing many people to login without having to move from their desk. The network provides instant access to a diverse range of individuals around the world which allows personal networks to be broadened and strengthened, thereby overcoming many of the limitations of traditional face-to-face networking such as small network size and lack of diversity. The interviewees gave examples where they had rapidly found partners for projects, introductions to people they wanted to meet, and answers to technical or business problems by a process of "asking the audience". This is an illustration of the "wisdom of crowds" phenomenon by Surowiecki (2005). A technical problem posted on the front page of Ecademy will soon have relevant

Table I Social networking in our case study businesses

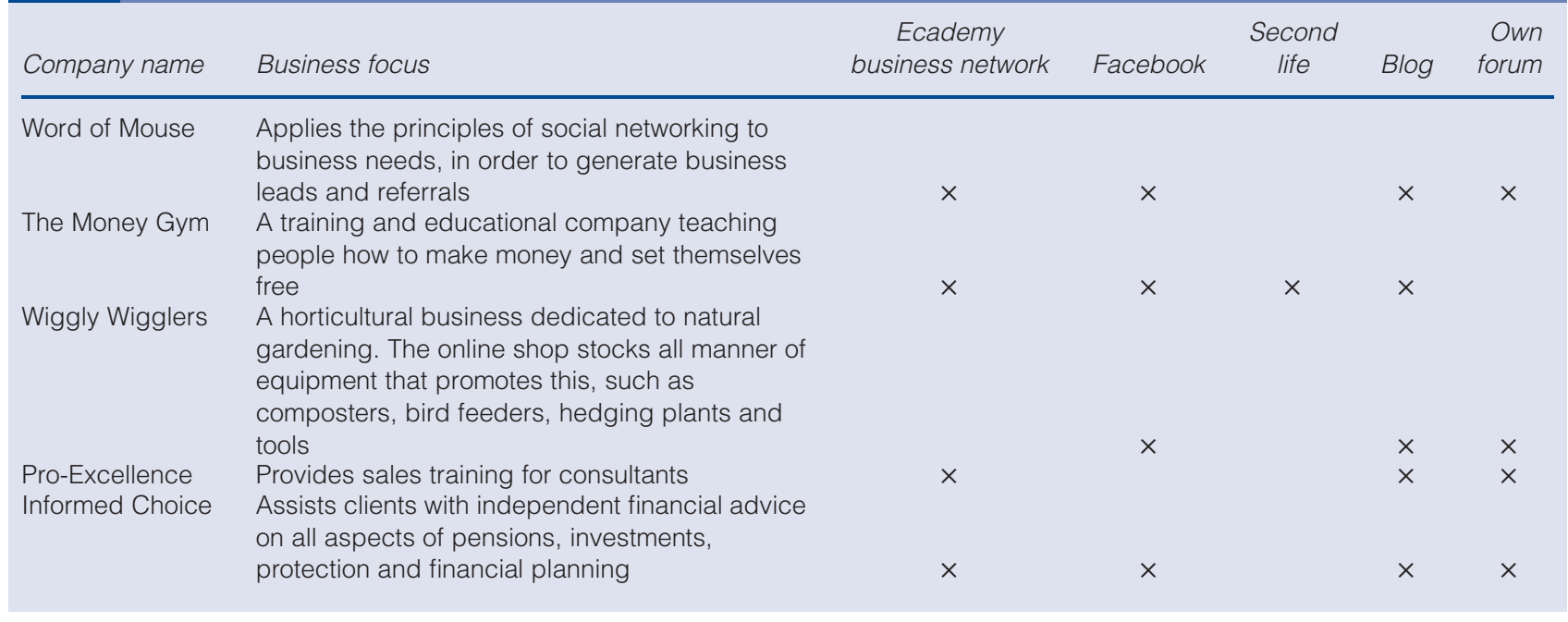


members competing to demonstrate their expertise by providing a solution. There is no quality control other than peer pressure, and the advisers need to guard their reputation jealously in what is effectively a "hot-house" environment that is self-policing. Because many Ecademy members are self-employed consultants, the "invisible hand" of the market place means that they offer free information because it builds their online profile as experts in their field to whom others can safely refer business. Satisfied enquirers can leave a glowing testimonial on the profile of the person who helped them, and such recommendations can encourage potential clients to make contact. All of our interviewees listed in Table I have won business contracts in this manner, and they display impressive feedback from satisfied customers. For example, Richard White of Pro Excellence built a club on Ecademy allowing his potential customers to debate with him and with each other. As the club has grown to have over 750 members its name has changed from "I hate Selling" to "Soft Selling" to "the Accidental Salesman". Richard says:

Many of the courses that I originally did free or nearly free I have since done commercially in a much more polished form as a result of having the opportunity to test and do feedback. It also generated leads through referrals and helped build my reputation through advocacy.

What drives this online collaboration forward in all the businesses we studied is a culture of trust - something that the conventional world does badly. "Givers gain" and "paying it forward" are phrases that occur frequently in Ecademy. There is an expectation that the best way of building influence over the longer term is to be seen as a "giver" of good quality practical information and advice. What seems to happen, over a period of time, is that these individuals obtain a reputation and position based on a combination of their expertise and "connectedness" which make them attractive to other players in the same space. Alliances build and "clumping" of commercial activity starts to take place in seed form. Usually there are between three and five individuals in a clump but these overlap and interlock. For example, one of our interviewees described the spectacular hyping of his book And Death Came Third. The publisher put together a significant package of benefits to anyone who bought the book on its launch day. Drawing upon his Ecademy contacts, other respected and influential individuals were encouraged to email their own networks with news of the offer. The result was the book got to number 2 on the Amazon bestseller list for that day.

Aside from Ecademy, other forms of online networking were also popular amongst our interviewees. Heather Gorringe of Wiggly Wigglers runs a regular and lengthy "stream of consciousness" podcast which tells her listeners what is going on in the business. Despite breaking normal podcasting rules by extending to over 30 minutes per episode, she has built up a global audience of 10,000 that for a small horticultural business is pretty good going. She has recently introduced a video channel and an active Facebook group into the mix as well. At the time of writing there are 497 members of the Wiggly Wigglers Facebook group and 123 current discussion topics within the forum. A popular topic of conversation in this community concerns the type of waste that can be safely composted, and the discussion includes some very personal information indeed! (see for yourself at: www. facebook.com/topic. php?uid = 3120520301\&topic = 4344) In Heather's words:

I do think it's all about goodwill. Our job is to keep goodwill with our customers, readers and listeners. Not only does that involve encouraging a conversation to find out what other people think, but also to make sure that if we have got that goodwill, that they bother to tell other people about us.

The potential of social networking for small businesses with limited marketing budgets was neatly summarized another interviewee, Mike Southon:

We need to understand social networks - how much is it going to change the world? The great thing is you can try things cheaply and then home in on what works.

Martin Bamford of Informed Choice is an IFA who has used social networking to back up his traditional local referral based business. He estimates that up to 40 percent of his business may eventually come through use of these techniques. He particularly recognizes the power of being a player in this environment in helping him to develop his understanding of how online marketing works. He says: 
Ecademy is packed full of early adopters - I wouldn't be so far on in my marketing if I wasn't exposed to the intensity of activity and the degree to which people share knowledge in my IFA club which is unheard of in the profession. It's also proved to be a good source of trusted suppliers.

\section{Virtual worlds - only for the brave}

Virtual communities such as Second Life pose some interesting challenges to entrepreneurial small businesses. According to its website:

Second Life is an online 3D virtual world imagined, created, and owned by its residents that offers a platform for communication, business, education, and organizational development to anyone who wants to try it.

Or, as the tagline aptly states, "It's just like real life, but you can fly." The platform offers a rich interactive experience for the consumer, and has already been well-tested in the area of gathering market research data from consumers and developing brand relationships. These communities allow for research and experimentation on the part of the organization at a fraction of the cost of real-world research and development. The behavior of an avatar can be instantly tracked and analyzed by organizations that are interested in studying consumer habits and reactions. There are a number of major corporations that have established a virtual presence within Second Life, including: IBM, Nike, BMW, Dell, Sun Microsystems, Sears, ABN AMRO and Sony. Motivations vary as to why each company joined the virtual world, and results are equally disparate as to their experiences so far, but according to Vedrashko (2006):

The world's creative flexibility coupled with the pioneering spirit of its residents makes Second Life an attractive sandbox for advertisers willing to experiment with new ideas that might be difficult or costly to try elsewhere.

Our case study businesses were intrigued by the possibility it offers of real-time, shared-space collaboration, something that is not always possible in the real world. Nicola Cairncross, owner of the Money Gym, focuses on helping divorced or single women take control of their financial destiny. She stands out from our sample as being the first to have a serious attempt to build Second Life into her marketing arsenal:

I can practice in Second Life as a real estate agency - buying and selling things in it. As a wealth coach it's a really good training tool. We find it also drives traffic to the real site.

For others it was a step too far. According to Martin Bamford, who is proactive in other forms of social networking:

I've not considered Second Life - If I go in there I'll never come out again - Ecademy is bad enough!

Such caution may well be justified as intellectual property theft, child pornography, virtual gambling and even terrorism are some of the cyber crimes now being reported in virtual worlds. A group calling themselves the Second Life Liberation Army recently executed a siege on Reebok's in-world store to protest against retail brands populating virtual worlds, and a video clip of the event even made it onto YouTube. It must be questioned how companies can be certain of the true demographics of the in-world consumer market, given that there is no obligation for people to replicate their real world personas (for example age, gender) within Second Life. Residents are heavily relied upon to police their own environment and report violators. Offenders' accounts can be suspended or shut-down for good, but it is possible for them to simply create a new account using a different real-world identity. At this stage, it remains to be seen whether the early business ventures into Second Life will pay off in the light of these difficulties.

\section{Discussion and conclusion}

Modern marketing requires a focus on innovation and the building of brand relationships. Marketing guru Seth Godin (2008) neatly captures the sea change in his latest book, rather bizarrely called "Meatball Sundae". As exemplified in the title, Seth notes that organizations have to be "remarkable" to succeed in the marketplace today, which comes down to getting 


\title{
"A recent example of a successful online community is www. getsatisfaction.com which provides a forum for customers to raise questions or complain about a wide range of companies, and for the resulting discussions to be displayed for other enquirers to search and view."
}

\begin{abstract}
"talked about virally" both online and offline. He is critical of organizations that attempt a "quick fix" by "bolting on" new forms of marketing communication to structures, processes and culture which have yet to evolve from their deeply embedded "command and control" preoccupations of the mass marketing era. The result of this approach is an unlikely mixture of incompatible ingredients which works for nobody - the "meatball sundae". The Walmart example described earlier may yet backfire if more broadly the company continues to maintain its well-established culture of secrecy and conformity which does not sit easily with authentic blogging within an online community.
\end{abstract}

A key issue that our case study businesses had to bear in mind when considering the use of social networks for communicating with customers, was the extent to which different segments of their customer base might be receptive to such approaches. Li (2007) has coined the term "social technographics" to describe the different ways in which consumers may behave online, which in turn governs how they will respond to approaches from companies via social networking channels. For example, a person defined as a "critic" is likely to comment on blog postings whereas a "spectator" is not, and someone categorized as "inactive" is unlikely to respond to any type of new media communication. Li highlights the importance for companies of understanding how their customers use new media, establishing what that means for how they should best communicate with them, and agreeing on how best to handle the possible loss of control associated with public display of negativity about the business on social networks.

There are also issues with regard to the privacy of personal data and how it will be used. Networks such as Facebook offer privacy controls where members can specify the extent of the information they wish to receive or share with individual friends. However, it is not always obvious how to set the controls and information may be unwittingly shared with the wrong people. Identity theft resulting from the harvesting of personal data that is posted on social networks is a growing concern. In addition, as we noted earlier, if social networks become too greedy in terms of the level of advertising that they permit, then users can very quickly shift their allegiance away from the network. Another warning note comes from recent research by the British Library (Manchester, 2008) which found that the skills and enthusiasm for Web 2.0 tools amongst the "Google generation" had been highly overrated, because while the respondents were prepared to use social networks for personal activities, they were skeptical about their relevance to the business world. Developments in the technologies themselves, as well as a reduction in costs, will mean that more and more information will be available to consumers. This results in unprecedented levels of transparency of dealings between businesses and their customers. A key challenge when engaging customers through these social networks is how to give away power and control while at the same time avoiding embarrassment to the company. According to Leadbetter (2008): "you are what you share", but he also notes: "The optimists describe the web as a conversation. Yet much of the web seems raucous and unruly. More like a bar-room brawl than a moderated discussion" (p. 4).

The positive experiences of our case study businesses with Ecademy support the former statement rather than the latter.

Despite these issues, the use of "Web 2.0" technologies by businesses is likely to increase significantly. Our work so far has focused on experiments by early adopter businesses, run 


\section{Keywords: Communities, Small enterprises, Networking, Communication}

by entrepreneurial individuals who are ahead of the curve and not afraid to take risks or try out new ideas. It is important to remember that these tools are still largely untested in more mainstream businesses. But consumers will increasingly expect companies to communicate with them through these tools. The concept of the "superfan" is much debated in marketing circles at the moment. This is considered by many to be the "holy grail" of online marketing creating a network of customers who are so positive about a brand that they do much of its marketing and sales themselves - and for free. Good examples of this are the TheAppleBlog.com and a Facebook Group called Apple Students (currently with 434,162 members), demonstrating how Apple has harnessed the power of these new social technologies to support one of the most successful brands in the world. On a smaller scale, the Wiggly Wigglers group we studied is well populated with "superfans". On balance we believe our case studies indicate that online communities will play a key role in the future of marketing because they replace customer annoyance with engagement, and control with collaboration for those firms brave enough to take the plunge. The businesses that prosper will be those who proactively embrace this new world, because they regard change as an opportunity rather than as a threat to be avoided at all costs.

\section{References}

Goad, R. and Mooney, A. (2008), "The impact of social networking in the UK", Hitwise/Experian Report. Godin, S. (2008), Meatball Sundae, Piatkus, New York, NY.

Leadbetter, C. (2008), We-think: The Power of Mass Creativity, Profile Books, London.

Li, C. (2007), "Social technographics", Forrester Research Paper.

Li, C. and Bernoff, J. (2008), Groundswell: Winning in a World Transformed by Social Technologies, Harvard Business School Press, Boston, MA.

Manchester, P. (2008), "Librarians challenge Web 2.0 youf-work myths", available at: www. regdeveloper.co.uk

(The) New York Times (2008), 3 March.

Surowiecki, J. (2005), The Wisdom of Crowds, Abacus, London.

Vedrashko, I. (2006), "Advertising in computer games", MSc thesis, Massachusetts Institute of Technology, Cambridge, MA.

Weber, L. (2008), Marketing to the Social Web: How Digital Customer Communities Build Your Business, John Wiley \& Sons, Hoboken, NJ.

\section{About the authors}

Lisa Harris is a Senior Lecturer in Marketing at Southampton University School of Management and Course Director of the MSc in Marketing Analytics. She is a Chartered Marketer and a Director of the Chartered Institute of Marketing. Lisa Harris is the corresponding author and can be contacted at: I.j.harris@soton.ac.uk

Alan Rae is Managing Partner of Al Consultants, which researches how small companies use IT and the internet.
To purchase reprints of this article please e-mail: reprints @ emeraldinsight.com Or visit our web site for further details: www.emeraldinsight.com/reprints 